\title{
OPEN Molecular surveillance of shiga toxigenic Escherichia coli in selected beef abattoirs in Osun State Nigeria
}

\author{
Femi Ayoade ${ }^{1,2 \bowtie}$, Judith Oguzie ${ }^{1,2}$, Philomena Eromon ${ }^{2}$, Omolola E. Omotosho ${ }^{3}$, \\ Tosin Ogunbiyi ${ }^{4}$, Testimony Olumade ${ }^{1,2}$, Kazeem Akano ${ }^{1,2}$, Onikepe Folarin ${ }^{1,2}$ \& \\ Christian Happi ${ }^{1,2}$
}

Shiga toxigenic strains of $E$. coli (STEC) known to be etiological agents for diarrhea were screened for their incidence/occurrence in selected abattoirs sources in Osogbo metropolis of Osun State, Nigeria using a randomized block design. Samples were plated directly on selective and differential media and $E$. coli isolates. Multiplex PCR analysis was used to screen for the presence of specific virulence factors. These were confirmed serologically as non-0157 STEC using latex agglutination serotyping kit. Sequence analysis of $\mathrm{PCR}$ products was performed on a representative isolate showing the highest combination of virulence genes using the $16 \mathrm{~S}$ gene for identification purposes only. Results showed that the average $\mathrm{cfu} / \mathrm{cm}^{2}$ was significantly lower in the samples collected at Sekona-2 slaughter slab compared with those collected at Al-maleek batch abattoir and Sekona-1 slaughter slab in ascending order at $\mathrm{P}=\mathbf{0 . 0 3}$. Moreover, the average $\mathrm{cfu} / \mathrm{cm}^{2} \mathrm{E}$. coli in samples collected from butchering knife was significantly lower when compared with that of the workers' hand $(P=0.047)$ and slaughtering floor $(P=0.047)$ but not with the slaughter table $(P=0.98)$ and effluent water from the abattoir house $(P=0.39)$. These data suggest that the abattoir type may not be as important in the prevalence and spread of STEC as the hygiene practices of the workers. Sequence analysis of a representative isolate showed $100 \%$ coverage and $96.46 \%$ percentage identity with Escherichia coli 0113:H21 (GenBank Accession number: CP031892.1) strain from Canada. This sequence was subsequently submitted to GenBank with accession number MW463885. From evolutionary analyses, the strain from Nigeria, sequenced in this study, is evolutionarily distant when compared with the publicly available sequences from Nigeria. Although no case of $E$. coli 0157 was found within the study area, percent occurrence of non-0157 STEC as high as $46.3 \%$ at some of the sampled sites is worrisome and requires regulatory interventions in ensuring hygienic practices at the abattoirs within the study area.

Shiga toxigenic strains of E. coli (STEC) are widely recognized as major pathogens for public health problems in developing countries and represent the leading etiological agent of diarrhea ${ }^{1,2}$. Serogroup O157 has been the most reported STEC in humans and has been found to be responsible for most infections, sporadic cases and outbreaks of bacterial enteritis in humans, globally. On the other hand, there is increasing evidence that nonO157 STEC are acquiring greater importance as they are frequently associated with sporadic outbreak of both mild and severe STEC disease in humans globally ${ }^{3,4}$.

Many of the STEC strains are found in the gastrointestinal tracts of domesticated farm animals, hence these form the principal source of human infections. The most noxious E. coli strains are those that are able to produce putative accessory virulence factors such as intimin (encoded by eaeA) and the plasmid-encoded enterohemolysin, encoded by enterohemorrhagic E. coli (EHEC) hlyA. Moreover, E. coli strains producing Shiga toxin type $2\left(s t x_{2}\right.$, encoded by $\left.s t x_{2}\right)$ appear to be more commonly responsible for serious complications such as HUS than

\footnotetext{
${ }^{1}$ Department of Biological Sciences, College of Natural Sciences, Redeemer's University, PMB 230, Ede, Osun State, Nigeria. ${ }^{2}$ African Center of Excellence for the Genomics of Infectious Diseases (ACEGID), Redeemer's University, PMB 230, Ede, Osun State, Nigeria. ${ }^{3}$ Biochemistry Unit, Department of Biological Sciences, Covenant University, Ota, Nigeria. ${ }^{4}$ Department of Biological Sciences, Mountain Top University, KM 12, Lagos-Ibadan Expressway, Prayer City, Ogun State, Nigeria. ${ }^{\circledR}$ email: ayoadef@run.edu.ng
} 
those producing only Shiga toxin type $1^{5}$. On the other hand, stx production is not restricted to serogroup O157 strains, as over 100 STEC serotypes have been isolated from humans with diarrheal illness ${ }^{4}$.

Contaminated raw meat is one of the main sources of food-borne illnesses. The risk of the transmission of zoonotic infections is also associated with contaminated meat ${ }^{6}$. While meat is usually consumed well-done in Nigeria, thereby limiting infections from meat consumption, contamination of water bodies from abattoir waste constitutes significant environmental and public health hazards ${ }^{6-8}$. Bacteria from abattoir waste discharged into water columns can subsequently be absorbed to sediments, and when the bottom stream is disturbed, the sediment releases the bacteria back into the water columns presenting long-term health hazards ${ }^{9}$. In Nigeria, numerous abattoirs dispose of their effluents directly into the streams and waterways without any type of treatment and the butchered meat is washed by the same water ${ }^{10}$.

The incidence of Shiga toxigenic E. coli varies by country, where such data is available. Shiga toxigenic E. coli infections have been reported for most parts of the world, including a number of African countries ${ }^{4}$, however, specific incidence data are not always collected or readily available in most sub-saharan African countries, especially in Nigeria.

There are two main types of abattoirs available within the study area, namely, the slaughter slab and the batch systems. Slaughter slabs are the most commonly found in Nigeria. They are usually established and operated by municipal and local authorities. These operate in well-built areas and conform to a good extent with the WHO guidelines for abattoirs. On the other hand, the batch type of slaughter system are those where animals are killed and processed sometimes on bare floor or on corrugated roofing sheets placed on the floor. These are usually located in abandoned buildings or under the shade of trees and open exposed grounds that a butcher might find suitable for the business ${ }^{11}$.

The present surveillance work is aimed at screening for the incidence/occurrence of Shiga Toxigenic Escherichia coli (STEC) in selected abattoirs and retail meat sources in Osogbo metropolis in Osun State of Nigeria, using molecular and serotyping methods. The work is expected to positively inform on best practices in the local abattoirs, and enhance effective planning, implementation and evaluation of public health practice within the study area.

\section{Results}

Frequency of occurrence of $E$. coli contamination. A total of 147 pure E. coli isolates were obtained from the entire study from the workers' hands, butchering knives, slaughtering tables, floors and effluent water at the different abattoir locations. Based on observation and interaction with the abattoir workers, water for the washing of hands are usually provided in all the three abattoirs included in this study. Workers in any of the abattoir hardly used this for hand cleansing but preferred to wipe their hands with handkerchiefs instead. Almaleek batch abattoir, overall mean colony forming units (cfu) $/ \mathrm{cm}^{2}$ was $46 \mathrm{cfu} / \mathrm{cm}^{2}$ (SEM 3.5). Mean $\mathrm{cfu} / \mathrm{cm}^{2}$ was significantly lowest in the samples taken from the butchering knife compared with workers' hand, slaughter tables, slaughtering floors and effluent water $3 \mathrm{cfu} / \mathrm{ml}$ (SEM 1) versus $16 \mathrm{cfu} / \mathrm{cm}^{2}$ (SEM 3.1$)$ versus $17 \mathrm{cfu} / \mathrm{cm}^{2}$ (SEM 3.1) versus $4 \mathrm{cfu} / \mathrm{cm}^{2}$ (SEM 1.5) versus $8 \mathrm{cfu} / \mathrm{ml}$ (SEM 0.6) respectively; $\mathrm{P}=0.006$ ] (Fig. $1 \mathrm{~A}$ ). In a post hoc comparison, the average cfu in samples from butchering knife and slaughtering floors were significantly lower than that of the workers' hand $(\mathrm{P}=0.04)$ and slaughtering table $(\mathrm{P}=0.02)$.

At the Sekona-1 abattoir, overall mean colony forming units per $\mathrm{cm}^{2}$ of all samples was $63 \mathrm{cfu} / \mathrm{cm}^{2}$ (SEM 2.1). Mean $\mathrm{cfu} / \mathrm{cm}^{2}$ was significantly higher in the samples taken from slaughtering floor compared with workers' hand, butchering knife, slaughter tables, and effluent water from the abattoir house $\left[25 \mathrm{cfu} / \mathrm{cm}^{2}\right.$ (SEM 4.6) versus $11 \mathrm{cfu} / \mathrm{cm}^{2}$ (SEM 3.1) versus $3 \mathrm{cfu} / \mathrm{cm}^{2}$ (SEM 1) versus $13 \mathrm{cfu} / \mathrm{cm}^{2}$ (SEM 1.2) versus $12 \mathrm{cfu} / \mathrm{ml}$ (SEM 1) respectively; $\mathrm{P}=0.007$ ] (Fig. $1 \mathrm{~B})$. Multiple comparison showed, mean $\mathrm{cfu} / \mathrm{cm}^{2}$ of cultures from all sampled items were similar except with the slaughtering floor.

At the Sekona-2 abattoir, overall mean $\mathrm{cfu} / \mathrm{cm}^{2}$ was $38 \mathrm{cfu} / \mathrm{cm}^{2}$ (SEM 7.5). Mean $\mathrm{cfu} / \mathrm{cm}^{2}$ was significantly lower in the culture of samples taken from butchering knife compared with those from workers' hand, slaughter tables, slaughtering floors and effluent water $\left[3 \mathrm{cfu} / \mathrm{cm}^{2}\right.$ (SEM 1.2) versus $12 \mathrm{cfu} / \mathrm{cm}^{2}$ (SEM 2.5) versus $4.5 \mathrm{cfu} /$ $\mathrm{cm}^{2}$ (SEM 1.5) versus $12 \mathrm{cfu} / \mathrm{cm}^{2}$ (SEM 2.6) versus $8 \mathrm{cfu} / \mathrm{ml}$ (SEM 0), respectively; $\mathrm{P}=0.03$ ] (Fig. 1C). In a post hoc analysis, mean colony forming units in samples from butchering knife was significantly lower compared with that of the workers' hand $(\mathrm{P}=0.047)$ and slaughtering floor $(\mathrm{P}=0.047)$ but not with the slaughter table $(\mathrm{P}=0.98)$ and effluent water from the abattoir house $(\mathrm{P}=0.39)$.

When all data were pooled together, mean $\mathrm{cfu} / \mathrm{cm}^{2}$ was significantly lower in the samples collected at Sekona-2 compared with those collected et al.-maleek and Sekona-1 $38 \mathrm{cfu} / \mathrm{cm}^{2}$ (SEM 7.5) versus $46 \mathrm{cfu} / \mathrm{cm}^{2}$ (SEM 3.5) versus $63 \mathrm{cfu} / \mathrm{cm}^{2}$ (SEM 2.1), respectively; $\mathrm{P}=0.03$ ] (Fig. 1D). In a post hoc analysis, mean colony form in samples collected from butchering knife was significantly lower compared with that of the workers' hand $(\mathrm{P}=0.047)$ and slaughtering floor $(\mathrm{P}=0.047)$ but not with the slaughtering table $(\mathrm{P}=0.98)$ and effluent water from the abattoir house $(\mathrm{P}=0.39)$.

Frequency of occurrence of STEC genes. A total number of pure isolates (147) were screened for the presence of six STEC genes. Of all the six genes screened, two (O157 and O111) did not amplify in any of the samples obtained from all three study sites (Fig. 2; Figure S1a-d, supplementary file). These results were corroborated through serotyping as none of the strains showed any visible agglutination with the O157 latex reagent. On the other hand, they caused a visible agglutination with the seroscreen latex reagent for detecting the 6 common non-O157STEC and were therefore identified as belonging to any of the non-O157 serogroups.

Similarly, hylA did not amplify in samples obtained from Al-maleek but amplified in samples from Sekona-1 and from Sekona-2 (Fig. 2D). 
A
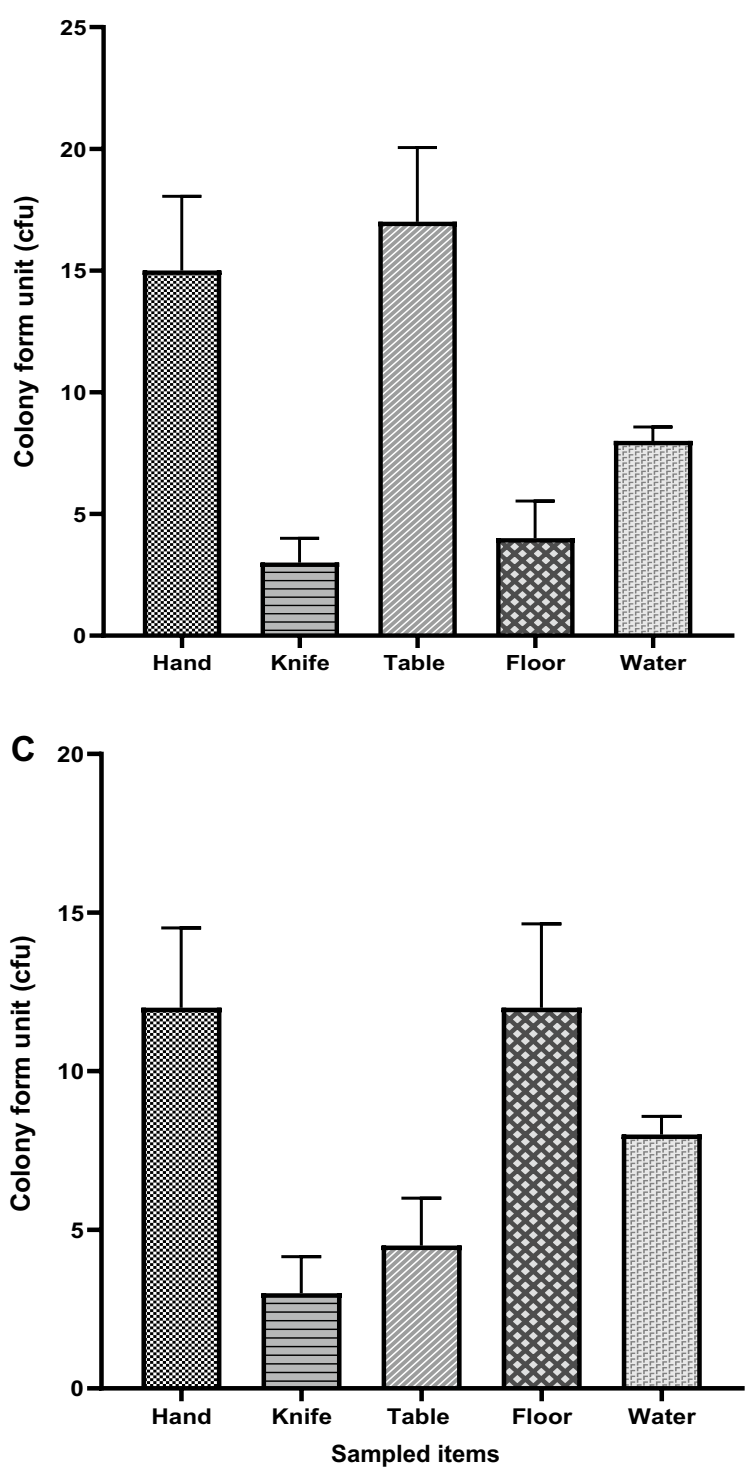

B

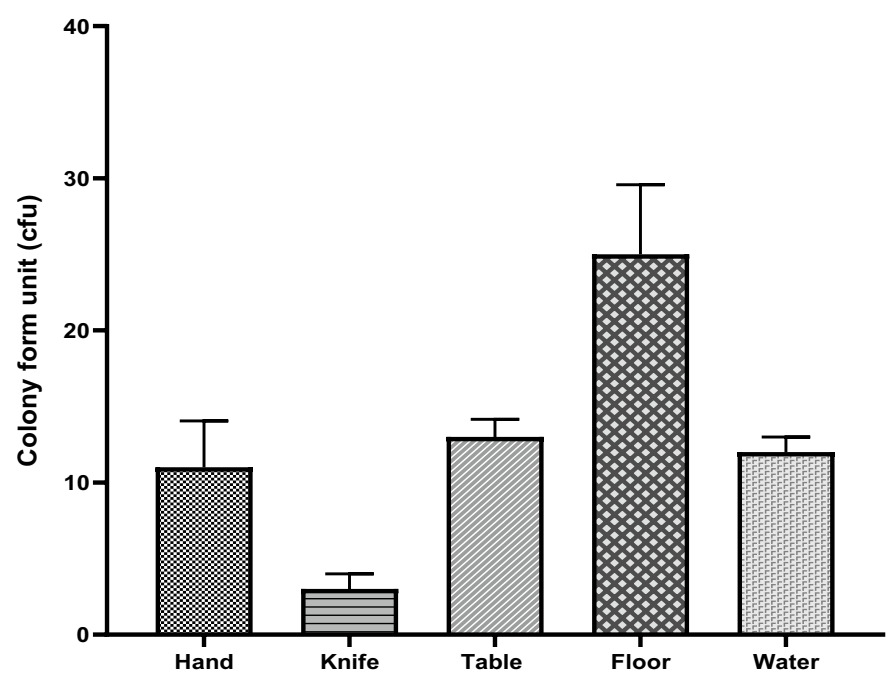

D

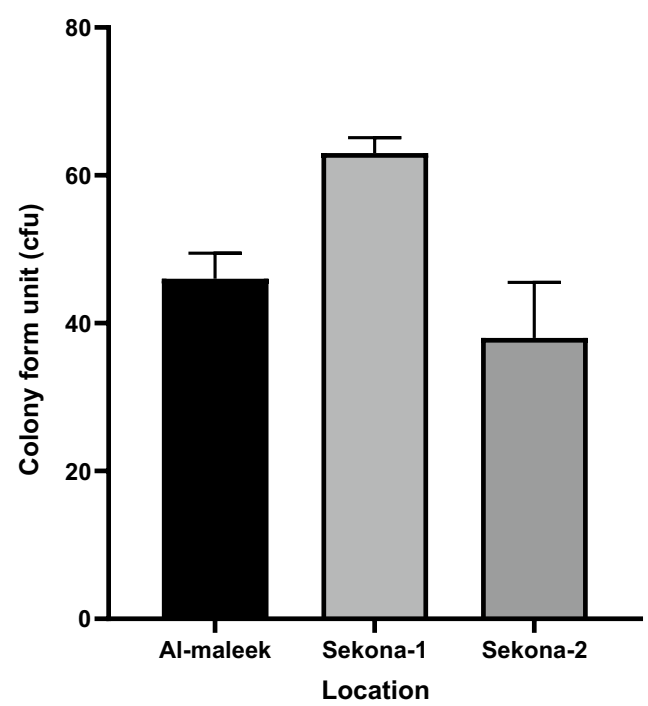

Figure 1. Average colony counts $(\mathrm{cfu} / \mathrm{ml})$ of E. coli colonies at the respective sampling locations (Workers' hands, slaughtering knife, slaughtering tables, floor and effluent water) in Al-maleek (A), Sekona-1 (B), Sekona-2 and in all three sites (D) pooled together.

When all data from all sampled items were pooled together according to sample sources, occurrence of $s t x_{2}$ gene was significantly more common in Al-maleek compared with Sekona-1 and Sekona-2. [12 of 21 isolates (i.e. $57.1 \%$ ) versus 5 of 16 (i.e. $31.3 \%$ ) versus 2 of 13 (i.e. 15.4\%) in Al-maleek, Sekona-1 and Sekona-2, respectively; $\mathrm{P}=0.02$ ] (Fig. 1D). However, distribution of $s t x_{1}$ and eae genes were similar in the isolates from all the three study locations. For $s t x_{1}$ : [8 of 21 isolates (i.e. $38.1 \%$ ) versus 4 of 16 (i.e. $25 \%$ ) versus 4 of 13 (i.e. $30 \%$ ) in Al-maleek, Sekona-1 and Sekona-2, respectively; P=0.69] (Fig. 1D). For eae: [13 of 21 (i.e. 61.9\%) versus 9 of 16 (i.e. $56.1 \%$ ) versus 3 of 13 (i.e. 23.1\%) in Al-maleek, Sekona-1 and Sekona-2, respectively; $\mathrm{P}=0.07$ ] (Fig. 2D). In further analysis, eae was significantly more common in Al-maleek compared with Sekona-2 $(\mathrm{P}=0.04)$ but not with Sekona-1 $(\mathrm{P}=0.99)$ (Fig. 2D).

It is noteworthy that one isolate (Se1-5-W5) from effluent water samples taken from Sekona-1 abattoir amplified 4 out of the 6 targeted genes ( $h l y \mathrm{~A}, s t x_{1}, s t x_{2}$ and eae). This isolate was singled out and set aside for molecular identification.

Sequencing and BLAST analysis of representative sample. The only isolate in which 4 out of the total of 6 genes considered were amplified was the isolate with identification number Se1-5-W5 (Fig. 2D). This isolate which was obtained from the effluent water from the Sekona abattoir was sequenced, primarily for identification by targeting the $16 \mathrm{~S}$ gene and compared with publicly available sequences available on NCBI for phylogenetic analysis (Fig. 3). Following BLAST analysis, the sequence showed $100 \%$ coverage with $97 \%$ 


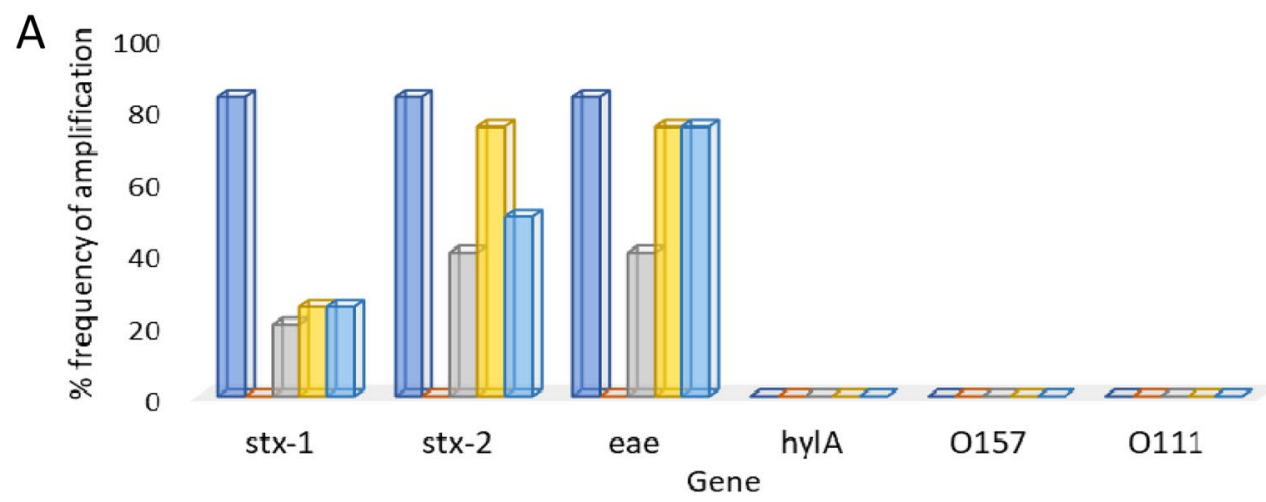

$$
\begin{aligned}
& \square \text { Hand } \\
& \square \text { Knife } \\
& \square \text { Table } \\
& \text { Floor } \\
& \square \text { Water }
\end{aligned}
$$

B

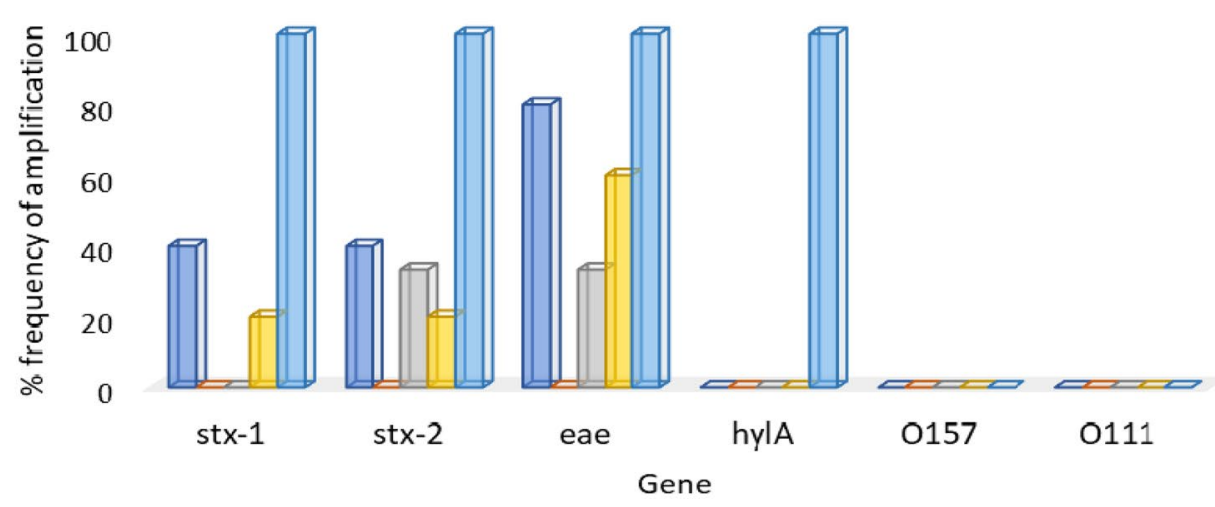

C
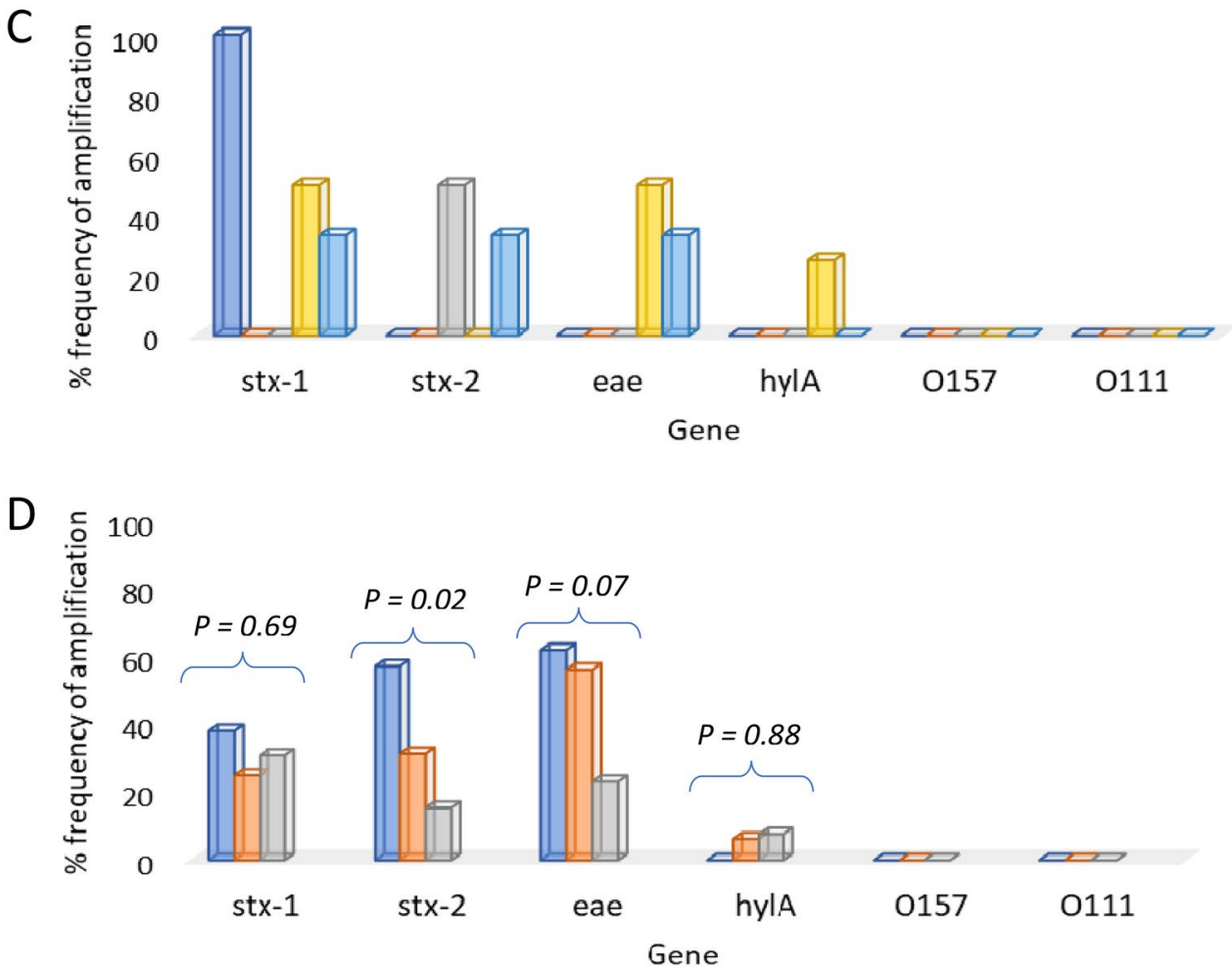

Figure 2. Distribution of stx-1, stx-2, eae, hylA, O157 and O111 genes among E. coli isolates from Al-maleek (A), Sekona-1 (B), Sekona-2 and in all three sites (D) pooled together.

$\square$ Hand

$\square$ Knife

$\square$ Table

Floor

$\square$ Water

Hand

Knife

$\square$ Table

Floor

Water

AL-maleek

$\square$ Sekona 1

$\square$ Sekona 2 


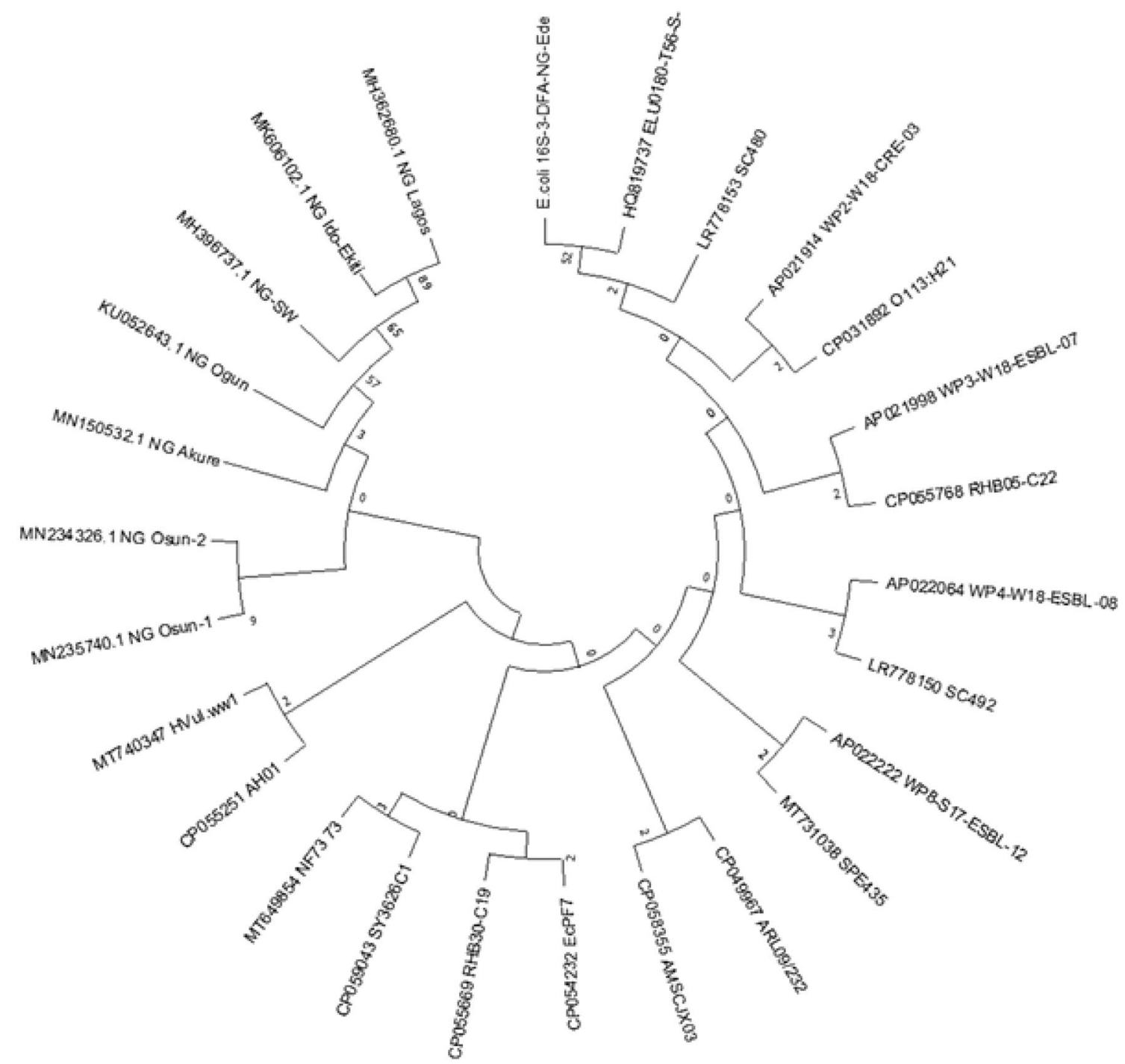

Figure 3. Phylogenetic analysis of $E$. coli sequence from Beef abattoir compared with publicly available sequences. Evolutionary analyses and phylogenetic tree were conducted in MEGA X version 7 (https://www. megasoftware.net/).

percentage identities to the ribosomal RNA gene of two uncultured organism clones with GenBank Accession numbers HQ791150.1 and HQ819737.1, a strain of Shigella spp. from London, UK, including a strain of Escherichia coli O113:H21 (GenBank Accession number: CP031892.1) strain from Canada with 96 percentage identity. From analyses, the strain from Nigeria, sequenced in this study, is evolutionarily distant when compared with the publicly available sequences from Nigeria (Fig. 3). The isolated 16S rRNA sequence was subsequently submitted to GenBank and registered with accession number MW463885.

\section{Discussion}

The present study investigated the prevalence of Shiga-toxigenic E. coli from selected beef abattoirs in Osun State. The results revealed that the average colony count $\left(\mathrm{cfu} / \mathrm{cm}^{2}\right)$ of distinct isolates of $E$. coli was significantly lower in the samples collected at Sekona-2 slaughter slab when compared with those collected at Almaleek (a batch type abattoir) and Sekona-1 slaughter slab type abattoir in ascending order (Fig. 1D). The current study shows the prevalence of $E$. coli was similar at the Sekona- 1 and Al-maleek abattoirs. This observation contradicts previous reports that favor Slaughter slabs over batch type simply because slaughter slabs operate in structurally well-built areas as opposed to batch type abattoirs where animals are killed and processed typically on corrugated roofing sheets placed on the floor ${ }^{11}$. This may indicate that mere structural design of an abattoir may not be a sole yardstick for rating propensity for E. coli contamination, evaluation of the abattoir practice and environmental burden must be considered.

In this evaluation, it was well demonstrated that hygienic practices of the abattoir workers is a more important factor in determining the rate of $E$. coli contamination in the abattoir setting than the structure of the abattoir, that is, whether it is batch or slaughter slab type. For instance, the post hoc analysis of the prevalence of $E$. coli colonies recovered from the sampled areas showed that the average $\mathrm{cfu} / \mathrm{cm}^{2}$ was consistently significantly higher 
on the workers' hand as well as on the slaughtering floor when compared with the colony count on the butchering knife (Fig. 1D). It appears that contamination is more likely to originate from the human activity during meat processing and that human activities may facilitate spreading the contaminants to the tables and floors and then to the effluent water.

Furthermore, the frequency of occurrence of the STEC genes data revealed that only four of the six targeted genes amplified in the E. coli colonies, the four genes include $s t x_{1}$, stx 2 , eae and hylA. The non-occurrence of $h l y A$ in samples obtained from Al-maleek batch abattoir further suggest that hygiene practices of the abattoir workers is more important in determining the rate of contamination rather than the abattoir type, since slaughter slabs are supposed to be structurally superior to batch type abattoirs. This hypothesis is further confirmed by the data showing that the workers' hands consistently displayed higher frequency of amplification of STEC genes when compared with other sample sources (Fig. 2A-C).

In addition, the present results agree with previous reports showing that cattle are the primary source of Shigatoxigenic strains of $E$. coli $i^{12-14}$. Our results are consistent with reports from similar studies where prevalence rates of up to $67 \%$ of STEC have been reported in cow hides, a human delicacy in the study area ${ }^{15}$. Similarly, several authors have reported high prevalence rates of STEC and non-STEC in meat sampled from Nigerian abattoirs ${ }^{16,17}$. The selected abattoirs in the present study primarily process cow meat.

Moreover, results from the present study showing that none of the isolates tested positive for the presence of $\mathrm{O} 157$ and $\mathrm{O} 111$ genes is not surprising. In studies where these have been reported in south-western Nigeria, the incidence rates has been found to be very low. For example, in nearby Ado-Ekiti ${ }^{18}$, a prevalence rate of $4.1 \%$ was reported in healthy cattle which is considerably lower than $14 \%$ non-O157 STEC strains recovered from cattle feces in Alberta, Canada ${ }^{19}$. The present study adds to the body of evidence that ruminants, particularly cattle represent the most important reservoir and source of human infection as a result of exposure to animal manure by contamination of food and water.

In addition, the present study shows the absence of O157 STEC strains within the study area (Figs. 1 and 2; Supplementary Figure S1), this is in contrast to reports from Lagos (which falls within the south-western geographical zone of Nigeria) where the isolation of E. coli O157:H7 from some food animals including goats have been reported ${ }^{20}$. On the other hand, the presence of non-O157 STEC strains at most of the study sites sampled in this study remains worrisome and a source for concern from the stance of public health.

Isolate Se1-5-W5 recovered from water samples from the Sekona-1 abattoir amplified 4 out of the 6 STEC genes screened for in the present study, representing the highest number and diversity of amplified genes found in the total of 50 isolates assessed. For this reason, this isolate was sequenced for identification purposes only and was identified as $\mathrm{O} 113: \mathrm{H} 21$ serotype. This particular strain has however been observed to amplify the eae gene (Fig. 2). Although not commonly encountered, eae-positive O113:H21 have been reported severally in literature ${ }^{21-23}$, with most of the reports coming from Brazil, where this serotype is the most frequent STEC serotype isolated from cattle and sometimes in humans ${ }^{24}$. The present result calls for further studies in the areas of sequencing for STEC genes in the selected isolates and assessment of the prevalence of O113:H21 serotypes in the Nigerian context.

On the other hand, even though the analysis of the sequencing data from the present study suggest closeness to a strain of Escherichia coli O113:H21 (GenBank Accession number: CP031892.1) strain from Canada with 96 percentage identity, this is distant from the definition of a species "match" which typically should be less than $1 \%$ divergence, that is, greater than $99 \%$ similarity. The data from the present study with $96 \%$ similarity may not be sufficient to comment on identification but only relatedness, since the only other organisms with closer relatedness (97\%) are from uncultured organism clones from New York, USA and a Shigella strain from London, U.K.

Results from the present study records no case of $E$. coli $\mathrm{O} 157$ within the study area, however, percentage occurrence of non-O157 STEC was as high as $46.3 \%$ at some of the sampled sites (Figs. 1 and 2). Up until now, zoonotic E. coli transmission was assumed to be more problematic in developed nations with highly industrialized agricultural systems, however, our results show that this may not be the case and the lack of reporting of high numbers of occurrence of E.coli transmissions may be due to lack of a surveillance system. Our study underscores the importance of developing a Laboratory-based Enteric Disease Surveillance (LEDS) system in Nigeria to stem the spread of noxious enteric diseases.

\section{Materials and methods}

Sample collection. Samples were obtained from 3 different sites of abattoirs within $50 \mathrm{~km}$ radius of Oshogbo, the capital city of Osun state Nigeria. Oshogbo is located at coordinates: $7^{\circ} 46^{\prime} \mathrm{N} 4^{\circ} 34^{\prime} \mathrm{E}$ and has a total area size of $47 \mathrm{~km}^{2}$ (18 sq. miles). The 3 abattoirs were selected for being the busiest abattoirs primarily devoted to slaughtering cattle within the study area, processing at least ten but not more than fifty cows slaughtered daily. One of the selected abattoirs, Al-maleek is a batch type while the other 2 abattoirs, Sekona-1 and Sekona-2 are slaughter slab type abattoirs. Using sterile swab $(3 \mathrm{~cm}$ long and $1 \mathrm{~cm}$ diameter) held by wooden stick and moistened with $0.1 \%$ peptone water, samples were obtained from slaughtering floors, slaughtering tables, butchering knives and worker's hands. Briefly, an area of $25 \mathrm{~cm}^{2}(5 \mathrm{~cm} \times 5 \mathrm{~cm})$ was marked on the surface from which sample is to be taken, the swabs were rubbed on the sites for around $30 \mathrm{~s}$ and then transferred to individual screwcapped test tube containing sterile maintenance medium $(0.85 \% \mathrm{NaCl}$ and $0.1 \%$ peptone $)$. Composite effluent water samples were collected using the grab method in sterile screw cap tubes. Samples were taken in triplicates and transported immediately to the laboratory for analyses. Samples were enumerated by using appropriate sterile dilution and spread plate methods, samples were incubated at $30^{\circ} \mathrm{C}$ for $18-24 \mathrm{~h}$. The distinct colonies on the plates were counted using a colony counter and the mean bacteria count per ml was calculated using the formula by dividing the average value of colony forming units on enumerated plates by the volume of sample dispensed unto agar and multiplying the product by the dilution factor. The average number of colonies in a particular dilu- 


\begin{tabular}{|c|c|c|c|}
\hline Primer & Sequence $\left(5^{\prime}-3^{\prime}\right)$ & Specificity $^{1}$ & Amplicon size (bp) \\
\hline \multicolumn{4}{|l|}{ Assay 1} \\
\hline stx1F & ATAAATCGCCATTCGTTGACTAC & \multirow{2}{*}{ nt $454-633$ of A subunit coding region of stx } & \multirow{2}{*}{180} \\
\hline stxiR & AGAACGCCCACTGAGATCATC & & \\
\hline stx2F & GGCACTGTCTGAAACTGCTCC & \multirow{2}{*}{$\begin{array}{l}\text { nt } 603-857 \text { of A subunit coding region of } s t x 2 \text { (including } s t x 2 \\
\text { variants) }\end{array}$} & \multirow{2}{*}{255} \\
\hline stx2R & TCGCCAGTTATCTGACATTCTG & & \\
\hline eaeAF & GACCCGGCACAAGCATAAGC & \multirow{2}{*}{$\begin{array}{l}\text { nt } 27-410 \text { of eaeA (this region is conserved between EPEC } \\
\text { and STEC) }\end{array}$} & \multirow{2}{*}{384} \\
\hline eaeAR & CCACCTGCAGCAACAAGAGG & & \\
\hline hlyAF & GCATCATCAAGCGTACGTTCC & \multirow{2}{*}{ nt 70-603 of EHEC hlyA } & \multirow{2}{*}{534} \\
\hline hlyAR & AATGAGCCAAGCTGGTTAAGCT & & \\
\hline \multicolumn{4}{|l|}{ Assay 2} \\
\hline O157F & CGGACATCCATGTGATATGG & \multirow{2}{*}{ nt 393-651 of $r f b E \mathrm{O} 157: \mathrm{H} 7$} & \multirow{2}{*}{259} \\
\hline O157R & TTGCCTATGTACAGCTAATCC & & \\
\hline O111F & TAGAGAAATTATCAAGTTAGTTCC & \multirow{2}{*}{ nt $24-429$ of ORF 3.4 of E. coli O111 $r f b$ region } & \multirow{2}{*}{406} \\
\hline O111R & ATAGTTATGAACATCTTGTTTAGC & & \\
\hline
\end{tabular}

Table 1. The PCR primers. ${ }^{1} n t$ nucleotide, ORF open reading frame ${ }^{29}$.

tion was expressed as the number of organisms or colony forming unit (CFU) of each sample and calculated into its $\log$ value. The microbiological data were expressed in $\log \mathrm{cfu} / \mathrm{cm}^{2}$ and $\log \mathrm{cfu} / \mathrm{ml}$ in case of swab and water respectively. A randomized block design was used. This design made it possible to compare the expected differences between frequency of occurrence of E. coli and STEC genes data from the two abattoir types (the blocks), while samples were collected from the slaughtering floors, slaughtering tables, butchering knives and worker's hands and effluent water samples (the treatments).

Consent. The purpose of the study was explained to the abattoir workers at each location with translation provided in the local language (Yoruba) and informed consent was obtained before taking sterile swabs of the workers' hands and knives. Each participant's right to refuse taking swabs from their knives or hands was respected at all times. This research was conducted according to the approved guidelines set by the Redeemer's University Research Ethics Committee, Redeemer's University, Ede, Osun State, Nigeria. This research was approved by the Redeemer's University Research Ethics Committee, Redeemer's University, Ede, Osun State, Nigeria.

Identification and serotyping of $E$. coli isolates. The samples were screened for the presence of members of the family Enterobacteriaceae, specifically E. coli, and these were targeted for use as indicators of microbial contamination. The inocula were plated directly on selective and differential media, namely, MacConkey (MAC) and Eosin Methylene Blue (EMB) agar. Furthermore, gas production and indole tests when isolates were grown at $44^{\circ} \mathrm{C}$ were used in order to confirm the isolates as E. coli. Subsequently, the confirmed $E$. coli isolates were stocked at $-4{ }^{\circ} \mathrm{C}$ and until used for downstream analyses such as genomic DNA extraction. The strains of E. coli $\mathrm{O} 157$ were identified culturally on the basis of inability to ferment sorbitol on SMAC agar and confirmed serologically as $\mathrm{O} 157$ by latex agglutination serotyping kit (Dryspot E. coli O157 latex test) for E. coli O157 (Oxoid, Basingstoke, UK) and (Dryspot E. coli serocheck and seroscreen latex test) for the detection of six non-O157 serogroups O26, O91, O103, O111, O128 and O145. The kit was used according to the manufacturer's specifications. The test reaction comprised of blue latex particles sensitized with specific rabbit antibody reactive with the relevant serogroup of E. coli (e.g., O157, O26, O111 etc.) as indicated on test card.

Statistical analysis. Data were analyzed using version 7 of Epi-Info software26 and GraphPad Prism version $8^{25,26}$. Simple graphs were plotted using GraphPad Prism version 8 and Microsoft Excel version $16^{27}$. Proportions were compared by calculating $\chi^{2}$ using Yates' correction, Fisher's exact or Mantel Haenszel tests. Normally distributed, continuous variables were compared by analysis of variance (ANOVA). Post-hoc comparisons of multiple parameters, where necessary, were done using Tukey Honestly Significant Difference Test (Tukey HSD). $p$ values of $<0.05$ were taken to indicate significant differences.

DNA extraction, PCR amplification and fragment purification. Genomic DNA was extracted from 50 randomly selected isolates from the entire study using the Excel Random Number Generator 28. Specifically, stock cultures of E. coli were incubated overnight in tryptic soy broth (TSB; Oxoid, England, U.K) then subcultured in fresh TSB $(20 \times$ dilution) and incubated for approximately $1 \mathrm{~h}$. The sub-culture was grown to reach ca. $4 \times 108 \mathrm{CFU} \mathrm{ml}^{-1}$, with an optical density between 0.5 and 0.6 at $600 \mathrm{~nm}$ (path length $1 \mathrm{~cm}$ ). All broth cultures were grown at $37^{\circ} \mathrm{C}$ and aerated with orbital shaking at $200 \mathrm{rpm}, 200 \mu \mathrm{l}$ of this was used for DNA extraction. Quick DNA ${ }^{\text {twa }}$ Fungal/Bacterial Miniprep kit was used in extracting the DNA by following manufacturer's instructions. The multiplexed PCR reactions were sectioned into 2 assays, namely assay 1 (comprising 4 sets of primers) and assay 2 (comprising 2 sets of primers) (Table 1). An aliquot of $5 \mu$ of the extracted DNA was used as a template in a $25 \mu \mathrm{l}$ PCR reaction mixture containing illustra ${ }^{\text {Tx }}$ PuReTaq ${ }^{\text {Tx }}$ Ready-To-Go ${ }^{\text {Tu }}$ PCR Beads, $1 \mu$ l each of forward and reverse for each of the primers, including $1.5 \mathrm{mM} \mathrm{MgCl}_{2}$ and $16.5 \mu \mathrm{l}$ of double distilled water. 
Samples were subjected to 35 PCR cycles, each consisting of $1 \mathrm{~min}$ of denaturation at $95^{\circ} \mathrm{C} ; 2$ min of annealing at $65^{\circ} \mathrm{C}$ for the first 10 cycles, decrementing to $60^{\circ} \mathrm{C}$ by cycle 15 ; and $1.5 \mathrm{~min}$ of elongation at $72{ }^{\circ} \mathrm{C}$, incrementing to $2.5 \mathrm{~min}$ from cycles 25 to 35 . PCR reaction mixtures were electrophoresed on $2 \%$ agarose gels and stained with ethidium bromide ${ }^{28}$.

Analysis of $E$. coli cultures by multiplex PCR and sequencing of representative isolates. Cultures from the $E$. coli isolates obtained from the sample locations were analyzed by PCR as described earlier, the $\mathrm{O} 157$ and $\mathrm{O} 111$ genes did not amplify in both the control and test isolates. However, during the course of data analyses, a particular isolate with isolate identification number Se1-5-W5, obtained from water effluent from the Sekona-1 abattoir site, observed to express the highest number of targeted genes was singled out for the purpose of identification only. Subsequently, Sanger sequencing was applied to this particular representative strain that displayed the highest number and diversity of targeted STEC genes for identification purposes only.

$25 \mathrm{ng}$ of the PCR product from the amplification of the $16 \mathrm{~S}$ gene of the representative strain was sequenced using the BigDye Terminator v3.1 on an ABI 3500 Genetic Analyzer from Life Technologies. The raw reads came from this cycle sequencing procedure. The whole genome was not sequenced.

Raw reads from Sanger sequencing were trimmed using BioEdit Sequence Alignment Editor (version 7.2.6) (https://bioedit.software.informer.com) with manual base calling where necessary. The resulting consensus sequence was then subjected to BLAST (Basic Local Alignment Search Tool) analysis for the identification of the organism. Alignment of the sequence, with other publicly available sequences from GenBank, was carried out using the ClustalW algorithm in Geneious Prime (version 2020.2.4). Evolutionary analyses were conducted in MEGA X ${ }^{29}$.

The evolutionary history was inferred by using the Maximum Likelihood method and Hasegawa-KishinoYano model $^{30}$. The tree with the highest log likelihood $(-3908.74)$ is shown. The percentage of trees in which the associated taxa clustered together is shown next to the branches. Initial tree(s) for the heuristic search were obtained automatically by applying Neighbor-Join and BioNJ algorithms to a matrix of pairwise distances estimated using the Maximum Composite Likelihood (MCL) approach, and then selecting the topology with superior $\log$ likelihood value. This analysis involved 25 nucleotide sequences from the $16 \mathrm{~S}$ sequences publicly available on the NCBI database used for the phylogenetic analyses. Evolutionary analyses were conducted in MEGA X ${ }^{29}$.

Received: 28 February 2021; Accepted: 15 June 2021

Published online: 07 July 2021

\section{References}

1. Chigor, V. N., Umoh, V. J., Smith, S. I., Igbinosa, E. O. \& Okoh, A. I. Multidrug resistance and plasmid patterns of Escherichia coli $\mathrm{O} 157$ and other $E$. coli isolated from diarrhoeal stools and surface waters from some selected sources in Zaria, Nigeria. Int. J. Environ. Res. Public Health 7(10), 3831-3841. https://doi.org/10.3390/ijerph7103831 (2010).

2. Ranjbar, R., Dehkordi, F. S., Shahreza, M. H. S. \& Rahimi, E. Prevalence, identification of virulence factors, O-serogroups and antibiotic resistance properties of Shiga-toxin producing Escherichia coli strains isolated from raw milk and traditional dairy products. Antimicrob. Resist. Infect. Control 7(1), 1-11. https://doi.org/10.1186/s13756-018-0345-x (2018).

3. Amézquita-López, B. A. et al. Antimicrobial resistance profiles of Shiga toxin-producing Escherichia coli O157 and Non-O157 recovered from domestic farm animals in rural communities in Northwestern Mexico. Antimicrob. Resist. Infect. Control 5(1), 1-6. https://doi.org/10.1186/s13756-015-0100-5 (2016).

4. Valilis, E., Ramsey, A., Sidiq, S. \& DuPont, H. L. Non-O157 Shiga toxin-producing Escherichia coli-A poorly appreciated enteric pathogen: Systematic review. Int. J. Infect. Dis. 76, 82-87. https://doi.org/10.1016/j.ijid.2018.09.00 (2018).

5. Ndegwa, E., Alahmde, A., Kim, C., Kaseloo, P. \& O’Brien, D. Age related differences in phylogenetic diversity, prevalence of Shiga toxins, Intimin, Hemolysin genes and select serogroups of Escherichia coli from pastured meat goats detected in a longitudinal cohort study. BMC Vet. Res. 16(1), 1-15. https://doi.org/10.1186/s12917-020-02479-0 (2020).

6. Akindolire, M. A. \& Ateba, C. N. Use of pulsed field gel electrophoresis genetic typing for tracing contamination with virulent Escherichia coli O157: H7 in beef-cattle producing farms. Gene Rep. 13, 59-65. https://doi.org/10.1128/MRA.01296-18 (2018).

7. Ayodele, O. A., Deji-Agboola, A. M., Akinduti, P. A. \& Faneye, A. O. Phylo-diversity of prevalent human E. coli O157: H7 with strains from retailed meat and fish in selected markets in Ibadan Nigeria. J. Immunoassay Immunochem. 41(2), 117-131. https:// doi.org/10.1080/15321819.2019.1694942 (2020).

8. Odjadjare, E. E. O. \& Ebowemen, M. J. Antibiogram of Pseudomonas isolates and potential public health impact of an abattoir effluent in Benin City, Nigeria. Afr. J. Clin. Exp. Microbiol. 21(3), 240-249. https://www.ajol.info/index.php/ajcem (2020).

9. Nafarnda, W. D. et al. Bacteriological quality of abattoir effluents discharged into water bodies in Abuja, Nigeria. Int. Sch. Res. Not. https://doi.org/10.5402/2012/515689 (2012).

10. Ogbonna, D. N. Distribution of microorganisms in water, soils and sediment from abattoir wastes in southern Nigeria. Int. J. Curr. Microbiol. Appl. Sci. 3(9), 1183-1200 (2014).

11. Ayoade, F. \& Olayioye, E. O. Microbiological assessment of housekeeping practices and environmental impact of selected abattoirs in Lagos and Ogun States of Nigeria. J. Appl. Biosci. 99, 9363-9372. https://doi.org/10.4314/jab.v99i1.2 (2016).

12. Effler, P. et al. Factors contributing to the emergence of Escherichia coli O157:H7 in Africa. Emerg. Infect. Dis. 7(5), 815-819. https:// doi.org/10.3201/eid0705.017507 (2001).

13. Naylor, S. W. et al. Lymphoid follicle dense mucosa at the terminal rectum is the principal site of colonization of enterohemorrhagic Escherichia coli O157:H7 in the bovine host. Infect. Immun. 71(3), 1505-1512. https://doi.org/10.1128/iai.71.3.1505-1512. 2003 (2003).

14. Authur, T. M. et al. Super shedding of Escherichia coli O157:H7 by cattle and the impact on beef carcass contamination. Meat Sci. 2010(86), 32-37. https://doi.org/10.1016/j.meatsci.2010.04.019 (2010).

15. Akanbi, B. O., Mbah, I. P. \& Kerry, P. C. Prevalence of Escherichia coli O157:H7 on hides and faeces of ruminants at slaughter in two major abattoirs in Nigeria. Lett. Appl. Microbiol. 53, 336-340. https://doi.org/10.1111/j.1472-765X.2011.03113.x (2011).

16. Ojo, O. E. et al. Potentially zoonotic shiga toxin-producing Escherichia coli serogroups in the faeces and meat of food-producing animals in Ibadan, Nigeria. Int. J. Food Microbiol. 142(1-2), 214-221. https://doi.org/10.1016/j.ijfoodmicro.2010.06.030 (2010). 
17. Kabiru, L. M., Bello, M., Kabir, J., Grande, L. \& Morabito, S. Detection of pathogenic Escherichia coli in samples collected at an abattoir in Zaria, Nigeria and at different points in the surrounding environment. Int. J. Environ. Res. Public Health 12(1), 679-691. https://doi.org/10.3390/ijerph120100679 (2015).

18. Oluyege, A. O. \& Famurewa, O. Shiga toxin and non-shiga toxin-producing Escherichia coli O157 from cattle, goats and chicken in Ado-Ekiti, South West, Nigeria. Int. J. Trop. Dis. Health 6(4), 108-118. https://doi.org/10.9734/IJTDH/2015/7352 (2015).

19. Renter, D. G., Bohaychuk, V., Van Donkersgoed, J. \& King, R. Presence of nonO157 Shiga toxin-producing Escherichia coli in feces from feedlot cattle in Alberta and absence on corresponding beef carcasses. Can. J. Vet. Res. 2007, 71230-71235 (2007).

20. Smith, S. I. et al. Plasmid profile of Escherichia coli 0157: H7 from apparently healthy animals. Afr. J. Biotechnol. 2(9), 322-324 (2003).

21. Panel on Biological Hazards. Public health risks associated with enteroaggregative Escherichia coli (EAEC) as a food-borne pathogen. EFSA J. 13(12), 4330 (2015)

22. Dos Santos, L. F., Irino, K., Vaz, T. M. I. \& Guth, B. E. C. Set of virulence genes and genetic relatedness of O113: H21 Escherichia coli strains isolated from the animal reservoir and human infections in Brazil. J. Med. Microbiol. 59(6), 634-640 (2010).

23. Dos Santos, L. F., Gonçalves, E. M., Vaz, T. M. I., Irino, K. \& Guth, B. E. C. Distinct pathotypes of O113 Escherichia coli strains isolated from humans and animals in Brazil. J. Clin. Microbiol. 45(6), 2028-2030 (2007).

24. Irino, K. et al. Serotypes and virulence markers of Shiga toxin-producing Escherichia coli (STEC) isolated from dairy cattle in São Paulo State, Brazil. Vet. Microbiol. 105, 29-36 (2005).

25. Epi Info Version 7: A Word Processing Database and Statistics Program for Public Health on IBM-compatible Microcomputers. Centers for Disease Control and Prevention, Atlanta (2020).

26. GraphPad Prism version 8 for Windows, GraphPad Software, San Diego (2020).

27. Microsoft Corporation 2018. Microsoft Excel version 16. https://office.microsoft.com/excel

28. Paton, A. W. \& Paton, J. C. Detection and characterization of shiga toxigenic Escherichia coli by using multiplex PCR assays for stx1, stx2, eaeA, enterohemorrhagic E. coli hlyA, rfb O111, and rfb O157. J. Clin. Microbiol. 36(2), 598-602. https://doi.org/10. 1128/JCM.36.2.598-602.1998 (1998).

29. Kumar, S., Stecher, G., Li, M., Knyaz, C. \& Tamura, K. MEGA X: Molecular evolutionary genetics analysis across computing platforms. Mol. Biol. Evol. 35(6), 1547-1549. https://doi.org/10.1093/molbev/msy096 (2018).

30. Hasegawa, M., Kishino, H. \& Yano, T. A. Dating of the human-ape splitting by a molecular clock of mitochondrial DNA. J. Mol. Evol. 22(2), 160-174. https://doi.org/10.1007/BF02101694 (1985).

\section{Acknowledgements}

This work is made possible in part by support from Flu Lab and a cohort of generous donors through TED's Audacious Project, including the ELMA Foundation, Mackenzie Scott, the Skoll Foundation, and Open Philanthropy. This work was also supported by grants from the National Institute of Allergy and Infectious Diseases (https:// www.niaid.nih.gov), NIH-H3Africa (https://h3africa.org) (U01HG007480 and U54HG007480), the World Bank grant (worldbank.org) (project ACE IMPACT).

\section{Author contributions}

F.A., J.O., O.F., P.E. and C.H. conceived and designed study. F.A., J.O., T.O., Tes.O. and O.O. conducted the experiments. F.A., J.O., T.O., Tes.O. and O.F. analyzed the samples and the experimental data. K.A. performed the statistical analyses and prepared the figures. F.A. wrote the manuscript. All authors reviewed and accepted the final version of the manuscript.

\section{Competing interests}

The authors declare no competing interests.

\section{Additional information}

Supplementary Information The online version contains supplementary material available at https://doi.org/ 10.1038/s41598-021-93347-w.

Correspondence and requests for materials should be addressed to F.A.

Reprints and permissions information is available at www.nature.com/reprints.

Publisher's note Springer Nature remains neutral with regard to jurisdictional claims in published maps and institutional affiliations.

(c) (i) Open Access This article is licensed under a Creative Commons Attribution 4.0 International License, which permits use, sharing, adaptation, distribution and reproduction in any medium or format, as long as you give appropriate credit to the original author(s) and the source, provide a link to the Creative Commons licence, and indicate if changes were made. The images or other third party material in this article are included in the article's Creative Commons licence, unless indicated otherwise in a credit line to the material. If material is not included in the article's Creative Commons licence and your intended use is not permitted by statutory regulation or exceeds the permitted use, you will need to obtain permission directly from the copyright holder. To view a copy of this licence, visit http://creativecommons.org/licenses/by/4.0/.

(c) The Author(s) 2021 